\title{
CaM kinase signaling induces cardiac hypertrophy and activates the MEF2 transcription factor in vivo
}

\author{
Robert Passier, ${ }^{1}$ Hong Zeng, ${ }^{2}$ Norbert Frey, ${ }^{1}$ Francisco J. Naya, ${ }^{1}$ \\ Rebekka L. Nicol, ${ }^{1}$ Timothy A. McKinsey, ${ }^{1}$ Paul Overbeek, ${ }^{3}$ \\ James A. Richardson, ${ }^{4}$ Stephen R. Grant, ${ }^{2}$ and Eric N. Olson ${ }^{1}$ \\ ${ }^{1}$ Department of Molecular Biology, The University of Texas Southwestern Medical Center at Dallas, Dallas, Texas, USA \\ ${ }^{2}$ Laboratory of Cardiac and Vascular Molecular Genetics, The Cardiovascular Research Institute, \\ University of North Texas Health Science Center at Fort Worth, Fort Worth, Texas, USA \\ ${ }^{3}$ Department of Cell Biology, Baylor College of Medicine, Houston, Texas, USA \\ ${ }^{4}$ Department of Pathology, The University of Texas Southwestern Medical Center at Dallas, Dallas, Texas, USA
}

Address correspondence to: Eric N. Olson, Department of Molecular Biology, The University of Texas Southwestern

Medical Center at Dallas, 6000 Harry Hines Boulevard, Dallas, Texas 75235-9148, USA.

Phone: (214) 648-1187; Fax: (214) 648-1196; E-mail: eolson@hamon.swmed.edu.

Received for publication September 27, 1999, and accepted in revised form March 28, 2000.

\begin{abstract}
Hypertrophic growth is an adaptive response of the heart to diverse pathological stimuli and is characterized by cardiomyocyte enlargement, sarcomere assembly, and activation of a fetal program of cardiac gene expression. A variety of $\mathrm{Ca}^{2+}$-dependent signal transduction pathways have been implicated in cardiac hypertrophy, but whether these pathways are independent or interdependent and whether there is specificity among them are unclear. Previously, we showed that activation of the $\mathrm{Ca}^{2+} / \mathrm{calmod}-$ ulin-dependent protein phosphatase calcineurin or its target transcription factor NFAT3 was sufficient to evoke myocardial hypertrophy in vivo. Here, we show that activated $\mathrm{Ca}^{2+} /$ calmodulin-dependent protein kinases-I and -IV (CaMKI and CaMKIV) also induce hypertrophic responses in cardiomyocytes in vitro and that CaMKIV overexpressing mice develop cardiac hypertrophy with increased left ventricular end-diastolic diameter and decreased fractional shortening. Crossing this transgenic line with mice expressing a constitutively activated form of NFAT3 revealed synergy between these signaling pathways. We further show that CaMKIV activates the transcription factor MEF2 through a posttranslational mechanism in the hypertrophic heart in vivo. Activated calcineurin is a less efficient activator of MEF2-dependent transcription, suggesting that the calcineurin/NFAT and CaMK/MEF2 pathways act in parallel. These findings identify MEF2 as a downstream target for CaMK signaling in the hypertrophic heart and suggest that the CaMK and calcineurin pathways preferentially target different transcription factors to induce cardiac hypertrophy.
\end{abstract}

J. Clin. Invest. 105:1395-1406 (2000).

\section{Introduction}

Hypertrophic growth is an adaptive response of the heart to a variety of pathological stimuli, including hypertension, myocardial infarction, endocrine disorders, and perturbations in sarcomeric function due to altered expression or mutations of contractile proteins. In response to hypertrophic signals, cardiomyocytes activate a cellular response characterized by an increase in cell size, sarcomere assembly, induction of fetal cardiac genes, and repression of genes encoding the corresponding adult isoforms (1-4).

Numerous studies indicate that alterations in intracellular $\mathrm{Ca}^{2+}$ signaling are a primary stimulus for the hypertrophic response. For example, stimulation with $\mathrm{Ca}^{2+}$ agonists (5), treatment with $\mathrm{Ca}^{2+}$ ionophores (6), or elevation of extracellular $\mathrm{Ca}^{2+}(7)$ results in hypertrophic responses in primary cardiomyocytes in vitro. Hypertrophic agents, including $\beta$-adrenergic agonists, angiotensin II (AngII), and endothelin-1 (ET-1) also activate $\mathrm{Ca}^{2+}$-dependent intracellular signaling systems
(8-10). Conversely, blockade of depolarization-induced $\mathrm{Ca}^{2+}$ entry in cardiomyocytes prevents the cellular and molecular changes associated with hypertrophy (5). Perturbations in $\mathrm{Ca}^{2+}$ handling have also been documented in hypertrophic cardiomyocytes with altered contractility due to aberrant expression of sarcomeric proteins (reviewed in ref. 11).

Recently, we showed that the $\mathrm{Ca}^{2+} /$ calmodulindependent protein phosphatase, calcineurin, can transduce hypertrophic signals in vivo and in vitro (12). Treatment of cultured cardiomyocytes with the calcineurin inhibitors cyclosporin A (CsA) and FK506 blocked the hypertrophic response to phenylephrine (PE) and AngII, and expression of activated calcineurin in the hearts of transgenic mice led to hypertrophy that progressed to dilated cardiomyopathy and sudden death (12). Moreover, treatment with CsA of several mouse models of hypertrophy arising from altered sarcomeric function or $\mathrm{Ca}^{2+}$-dependent signaling has been shown to prevent or diminish hypertrophy $(13,14)$. 
Overexpression of the calcineurin inhibitory protein Cabin/Cain is also sufficient to block myocardial hypertrophy in vitro (15). Induction of the hypertrophic response by calcineurin appears to be mediated, at least in part, by dephosphorylation of the $\mathrm{Ca}^{2+}$-regulated transcription factor NFAT3, a cofactor for the cardiac zinc-finger transcription factor GATA-4 (12).

Because the calcineurin/NFAT3 signal transduction pathway is only one of several signaling systems shown to be capable of inducing hypertrophy, an important question is whether this pathway is integrated with, or independent of, other hypertrophic signaling systems. Although our previous studies demonstrated that activated calcineurin is sufficient, and in some situations necessary, for hypertrophy (12), calcineurin activation does not appear to be sufficient to account for all forms of hypertrophy. There are reports, for example, that hypertrophy in spontaneously hypertensive rats and in response to pressure overload in aortic-banded rats and mice is not prevented by CsA or FK506 (16-21), although other reports have concluded that these calcineurin inhibitors can prevent or reduce hypertrophy under these conditions $(13,18,22)$. Postnatal growth of the heart also occurs normally in mice maintained on calcineurin inhibitors (12), and certain transgenic mouse lines do not respond to calcineurin inhibition (13), indicating the existence of calcineurin-independent mechanisms for cardiac growth.

There is substantial evidence suggesting that the intracellular $\mathrm{Ca}^{2+}$-binding protein, calmodulin, may be a key regulator of cardiac hypertrophy. For example, overexpression of calmodulin in the hearts of transgenic mice induces hypertrophy (23), and treatment of cultured cardiomyocytes with the calmodulin antagonist W-7 prevents hypertrophy in response to $\alpha$-adrenergic stimulation and $\mathrm{Ca}^{2+}$ channel agonists (5). Calcineurin and the multifunctional CaMK are well-characterized downstream targets of calmodulin regulation. Indeed, activated CaMKII has been shown to induce the hypertrophic-responsive gene atrial natriuretic factor (ANF) in primary cardiomyocytes in vitro, although it cannot activate the complete hypertrophic response (24). The CaMKII inhibitor KN-62 can also block ANF release in electrically paced or endothelin-1-treated atrial cardiomyocytes in vitro $(25,26)$. Recently, cardiac CaMK activity was also reported to be elevated in patients with dilated cardiomyopathy $(27,28)$. However, whether CaMK signaling is sufficient for hypertrophic growth in vivo has not been investigated. The potential involvement in cardiac hypertrophy of CaMK isoforms other than CaMKII has also not been studied.

In the present study, we investigated the relationship between CaMK signaling and the calcineurin/NFAT3 pathway in cardiomyocytes in vivo and in vitro. We show that activated CaMKI and CaMKIV can induce the hypertrophic response in primary neonatal cardiomyocytes and that CaMKIV synergizes with activated NFAT3 to stimulate hypertrophy in vivo. Using a unique transgenic mouse line, harboring a lac $Z$ transgene under transcriptional control of the consensus binding site for the transcription factor MEF2, which has been implicated in $\mathrm{Ca}^{2+}$-dependent transcription (29), we also show that signaling by CaMKIV, but not calcineurin, potently stimulates MEF2 activity through a posttranslational mechanism in the heart in vivo. These findings identify MEF2 as a downstream target for CaMK signaling in the heart and suggest that $\mathrm{Ca}^{2+} /$ calmodulin-dependent signaling pathways controlled by CaMK and calcineurin act cooperatively and in parallel to preferentially activate distinct transcriptional targets in the heart.

\section{Methods}

Transfection assays. An ANF-luciferase reporter was generated by subcloning $700 \mathrm{bp}$ of the ANF proximal upstream promoter sequence (30) in pGL3 (Promega Corp., Madison, Wisconsin, USA). For the generation of the $\alpha$-skeletal actin-luciferase reporter, 420 bp of $\alpha$ skeletal actin proximal upstream promoter sequence (31) was subcloned in pGL3. Activated forms of calcineurin, CaMKI and CaMKIV, all lacking the calciumdependent domains in their $\mathrm{COOH}$-termini, were subcloned in pCDNAI. Primary rat cardiomyocytes were transiently transfected in six-well plates with the ANFluciferase reporter (50 ng/well) or the $\alpha$-skeletal actinluciferase reporter $(50 \mathrm{ng} /$ well) in the presence of expression vectors for calcineurin, CaMKI, or CaMKIV alone or in combination. The total amount of DNA for each transfection was $70 \mathrm{ng} /$ well. Empty pCDNAI was used to normalize DNA amounts. CsA was added to cardiomyocyte cultures immediately before transfection at a final concentration of $400 \mathrm{nM}$. Forty-eight hours later, cells were harvested and luciferase assays were performed with a Luciferase assay kit (Promega Corp.).

Creation of transgenic mice and Southern analysis. An expression plasmid encoding a truncated form of human CaMKIV, spanning the first 317 amino acids (kindly provided by T. Chatila, Washington University School of Medicine, St. Louis, Missouri, USA), was subcloned into the Sall site of pBluescript containing the $\alpha$ myosin heavy chain promoter (32). This CaMKIV construct contains the catalytic domain, but lacks the $\mathrm{COOH}$-terminal calmodulin-binding domain, resulting in constitutive activation of the enzyme (33). The CaMKIV sequence was preceded by a flag-tag (eight amino acids) and a Kozak consensus sequence. At the $\mathrm{COOH}$-terminus of CaMKIV, the human growth hormone (HGH) poly-A tail was included. Plasmid DNA was removed by NotI digestion, and the linearized CaMKIV construct was gel isolated and purified. The CaMKIV construct was eluted in $10 \mathrm{mM}$ Tris- $\mathrm{HCl}(\mathrm{pH}$ 7.8) and 0.1 mM EDTA (pH 8.0).

FVB mice were superovulated by standard procedures, and fertilized eggs were injected with the linearized DNA ( $2 \mathrm{ng} / \mu \mathrm{L})$. The injected embryos were transferred to the oviducts of pseudopregnant FVB mice. Offspring were analyzed for the presence of the transgene by Southern analysis of genomic DNA using a ${ }^{32}$ P-labeled HGH-fragment as a probe. 
MEF2 indicator mice harbor a lacZ transgene linked to the hsp68 basal promoter and three tandem copies of the MEF2 site from the desmin enhancer. The creation of these mice and the expression pattern of lac $\mathrm{Z}$ during embryogenesis have been described elsewhere (34).

Immunoprecipitation and Western blot analysis. Brain and heart tissues from wild-type and CaMKIV transgenic mice were minced in $1 \mathrm{~mL}$ lysis buffer containing 50 mM HEPES (pH 7.0), $250 \mathrm{mM} \mathrm{NaCl}, 0.1 \% \mathrm{NP} 40,5 \mathrm{mM}$ EDTA, and $1 \mathrm{mM}$ PMSF, EDTA-free complete proteinase inhibitor (Roche Molecular Biochemicals, Indianapolis, Indiana, USA). Four micrograms of anti-Flag $\mathrm{mAb}$ (Sigma Chemical Co., St. Louis, Missouri, USA) or $1 \mu \mathrm{g}$ of anti-CaMKIV mAb (Transduction Laboratories, Lexington, Kentucky, USA) and $25 \mu \mathrm{L}$ of protein A/G beads were added to $500 \mu \mathrm{g}$ of protein from the different tissue extracts and incubated overnight at $4^{\circ} \mathrm{C}$ on a platform rocker. After three washes in lysis buffer, precipitated proteins were resolved by SDS-PAGE and transferred to PVDF membranes and immunoblotted with the anti-CaMKIV mAb. Proteins were visualized using a chemiluminescence system (Santa Cruz Biotechnology Inc., Santa Cruz, California, USA). As a CaMKIV-positive control, $10 \mu \mathrm{L}$ of Jurkat cell lysate (Transduction Laboratories) was used.

Histology and morphometric analysis. Hearts from wildtype and transgenic mice were collected and cut at the midsagittal level and parallel to the base of the heart. Hearts were fixed overnight in $4 \%$ paraformaldehyde buffered with PBS, routinely processed, and paraffin embedded. Hearts were sectioned at $4 \mu \mathrm{m}$ and stained with hematoxylin and eosin. Myocyte cross-sectional areas were measured from wild-type and CaMKIV transgenic heart tissue sections $(n=6$, each) using a computerized morphometric system (Scion Image; National Institutes of Health, Bethesda, Maryland, USA). All wild-type and transgenic sections were measured at the same magnification in different regions of the heart (left and right ventricle, septum and papillary muscle). Myocyte cross-sectional area was measured per nucleus, and only myocytes that were cut in the same direction were included in the measurements. As criteria, the position and shape of the nucleus within the myocyte were used. All measurements were obtained by an examiner blinded to the genotype of the animals.

Assays for lac $Z$ activity. $\beta$-Galactosidase assays were performed on cardiac extracts from MEF2-indicator mice as described previously (35) under conditions of linearity with respect to time and protein concentration.

RNA isolation and Northern bybridization analysis. Hearts from wild-type and CaMKIV transgenic mice were isolated, frozen in liquid nitrogen, and stored at $-80^{\circ} \mathrm{C}$. Tissues were homogenized in Trizol (GIBCO BRL, Grand Island, New York, USA), extracted by chloroform, and precipitated by isopropyl alcohol. For Northern analysis, $15 \mu \mathrm{g}$ of total RNA was separated on a $1.5 \%$ formaldehyde/MOPSagarose gel, blotted to nitrocellulose, and hybridized with ${ }^{32} \mathrm{P}$-labeled probes for ANF, $\alpha \mathrm{MHC}$, and
GAPDH. After washing, filters were exposed to Phosphor screens and scanned using the Phosphor Imager (Molecular Dynamics, Sunnyvale, California, USA). RNA levels were quantitated using ImageQuant software (Molecular Dynamics). Expression levels were corrected for GAPDH mRNA levels.

Transthoracic echocardiography. Cardiac function of wild-type and transgenic mice was evaluated noninvasively with echocardiography. Mice were anesthetized with $2.5 \%$ Avertin (15 $\mu \mathrm{L} / \mathrm{g}$ body weight) (36). The ventral chest was shaved and the animal placed on a thermally controlled table in a slight left lateral decubitus position. Echocardiography was performed using a Hewlett Packard (Andover, Massachusetts, USA) Sonos 5500 Ultrasound system with a 12-Mhz transducer. Heart rate was determined by ECG analysis. At least three independent $\mathrm{M}$-mode measurements per animal were obtained by an examiner blinded to the genotype of the animal. Left ventricular chamber diameter in end-systole (LVESD) and end-diastole (LVEDD), interventricular septum wall thickness in end-systole (IVSS) and end-diastole (IVSD), and left ventricular posterior wall thickness in end-systole (LVPWS) and end-diastole (LVPWD), as well as left ventricular fractional shortening $(\mathrm{FS} \%=[(\mathrm{LVEDD}-\mathrm{LVESD}) / \mathrm{LVEDD}] \times 100)$, were determined in a short axis view at the level of the papillary muscles. Echo left ventricular mass (LVm) was calculated as: $L V m=(\text { IVSD + LVEDD + LVPWD })^{3}-$ $\operatorname{LVEDD}^{3}(37)$.

Gel mobility shift assays. Gel mobility shift assays using cardiac nuclear extracts were performed as described elsewhere (38). For supershift experiments, $1 \mu \mathrm{L}$ of antiMEF2A antibody (C-21; Santa Cruz, Biotechnology Inc.) was added to the reaction.

Statistical analysis. All data are presented as mean \pm SEM. Statistical significance of differences was calculated using a Student's $t$ test. Significance was accepted at the level of $P<0.05$.

\section{Results}

Activation of bypertrophic-responsive gene promoters by CaMKI and-IV. To begin to investigate the potential role of CaMK signaling in cardiac hypertrophy, we tested whether activated forms of CaMKI and CaMKIV, lacking the COOHterminal regulatory region required for $\mathrm{Ca}^{2+} /$ calmodulindependent regulation, could activate the promoters of the ANF and $\alpha$-skeletal actin genes linked to luciferase in transiently transfected cardiomyocytes. Consistent with the known responsiveness of these promoters to hypertrophic signals, activity of both promoters was upregulated by CaMKI and CaMKIV (Figure 1). These promoters were also activated to comparable levels by calcineurin (Figure 1). Expression of CaMKI and IV together did not result in additional activation of the $A N F$ or $\alpha$-skeletal actin promoters above that seen with either kinase alone. In contrast, the maximal effects of calcineurin and CaMKI or -IV were additive. These results suggested that these CaMKs acted through a common pathway to activate the hypertrophic response and that this pathway was sepa- 
Figure 1

CaMKI and -IV activate hypertrophy-responsive cardiac promoters through a calcineurin-independent mechanism. Transient transfection of cardiomyocytes with ANF-luciferase promoter (a) or $\alpha$-skeletal actin-luciferase (b) and expression vectors encoding activated calcineurin (CN), CaMKIV, or CaMKI in the presence or absence of cyclosporin A (CsA), as indicated. Data are presented as mean \pm SEM. All transfections were performed in triplicate.

rate from the calcineurin pathway.

To investigate further the possible involvement of calcineurin in hypertrophic signaling by CaMKI and -IV, we tested the effects of CsA on induction of the ANF and $\alpha$-skeletal actin promoters by these kinases (Figure 1). CsA completely blocked hypertrophic signaling by calcineurin and, unexpectedly, partially affected activation by CaMKI and -IV. In the presence of both calcineurin and these CaMKs, CsA reduced expression of the ANF and $\alpha$-skeletal actin promoters approximately to the level observed with CsA and CaMKI or -IV alone, which was substantially higher than the level seen with CsA and calcineurin. We conclude that the calcineurin and CaMK pathways are cooperative and that calcineurin may be required for maximal responsiveness to CaMK, but calcineurin activation cannot account for the complete response to CaMKI and -IV.

Creation of $\alpha M H C-C a M K I V$ transgenic. In light of the ability of CaMKI and -IV to induce hypertrophicresponsive promoters in primary cardiomyocytes, we extended our studies to investigate whether CaMK signaling could also induce cardiac hypertrophy in vivo, by generating mice that expressed activated CaMKIV in the heart, under control of the $\alpha \mathrm{MHC}$ promoter. Five founders carrying the CaMKIV transgene were obtained. One of the founders died at 3 weeks of age with an estimated copy number of 50 . Three of the surviving lines had a single copy of the transgene, and one line had three copies. Founder transgenic mice were bred to FVB mice to generate F1 offspring. Transgene
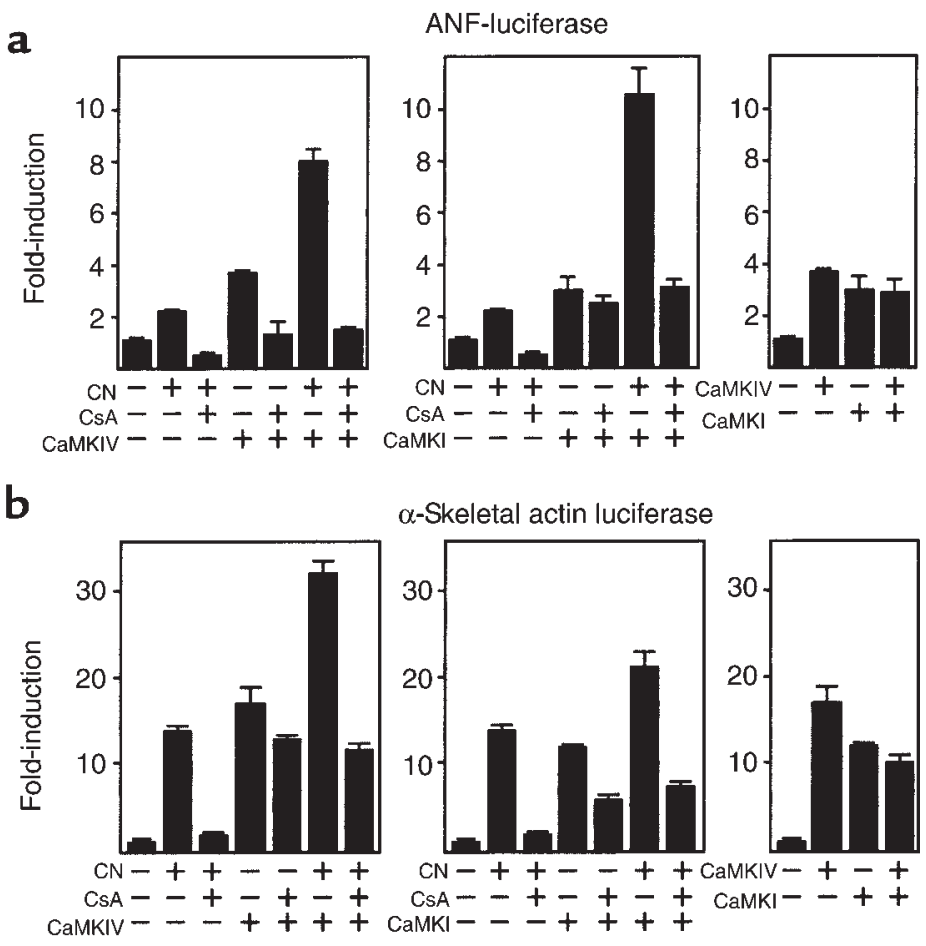

\section{Figure 2}

Western analysis of immunoprecipitated CaMKIV proteins. Brain and heart extracts $(500 \mu \mathrm{g})$ from wild-type and CaMKIV transgenic (CaMKIV-Tg) mice were either immunoprecipitated with antiCaMKIV mAb (lanes 2-4) or with anti-Flag mAb (lanes 5 and 6). Immunoprecipitates were separated by SDS-PAGE electrophoresis and subjected to Western analysis using the anti-CaMKIV antibody. As a positive control, $10 \mu \mathrm{L}$ of Jurkat cells lysate was used (lane 1). ATruncated CaMKIV protein. IgH, immunoglobulin heavy chains. expression was determined by Northern analysis using a probe specific to the coding region of human CaMKIV. All transgenic lines expressed the CaMKIV transgene in the heart (data not shown).

The level of expression of CaMKIV protein in hearts of $\alpha$ MHC-CaMKIV transgenic mice was determined by immunoprecipitation and Western blot analysis. As a positive control, parallel assays were performed on extracts from brain, the tissue with highest levels of CaMKIV expression (39). As seen in Figure 2, immunoprecipitations of brain extracts with CaMKIV antibody yielded the predicted $61-\mathrm{kDa}$ CaMKIV protein. To determine whether the CaMKIV transgenic mice expressed the truncated CaMKIV protein, heart extracts from transgenic mice were immunoprecipitated with anti-CaMKIV or anti-Flag $m A b$ and immunoblotted with anti-CaMKIV. The CaMKIV anti- 
body used in these experiments recognizes the $\mathrm{NH}_{2}$ terminus of CaMKIV and therefore detects the endogenous as well as the truncated CaMKIV protein. Both anti-Flag and anti-CaMKIV immunoprecipitations of the transgenic heart extracts demonstrated clearly the expected $40-\mathrm{kDa}$ CaMKIV truncated protein. The exogenous CaMKIV protein was expressed at a level approximating the level of CaMKIV expression in brain, which has been reported to be 50- to 100-times higher than the level in heart (39). The immunoglobulin heavy chain band migrates slightly below the predicted position of endogenous CaMKIV. This precluded reliable detection of the low level of endogenous CaMKIV protein in cardiac extracts.

Cardiac hypertrophy in vivo in response to activated CaMKIV expression. Examination of the hearts of $\alpha M H C-C a M K I V$ transgenic mice beginning at 1 month of age revealed moderate enlargement. At 8, 12, and 24 weeks of age, the heart weight/body weight ratios of the transgenics were significantly increased by $28 \%, 38 \%$ and $25 \%$, respectively (Figure $3 a$ and Figure 4).There was no difference between body weight from wild-type and transgenic mice, indicating that the increases of heart weight/body weight ratios were due to an increase in heart weight. In all four transgenic lines, an increase of heart weight/body weight ratio was observed, although the rate of progression of cardiac disease was most severe in the line with three copies of the transgene. The transgenic line with an estimated 50 copies of the transgene, which died at 3 weeks of age, showed extreme dilated cardiomyopathy (data not shown). The early lethality in this animal and the fact that viable transgenic lines had only one to three copies of the transgene may indicate that activated CaMKIV is a highly potent hypertrophic stimulus that can only be tolerated at relatively low levels. Cardiomyocyte areas were not increased in 6-week-old CaMKIV transgenic hearts, moderately increased at 8 weeks, and significantly increased at 20 weeks of age (Figure $3 \mathrm{~b}$ and Figure 4f), indicating a slow progression of cardiac hypertrophy, as suggested by the heart weight/body weight ratios.

We examined expression of the hypertrophic-responsive cardiac genes, $A N F$ and $\alpha M H C$, in CaMKIV transgenic mice by Northern analysis of RNA from heart. As shown in Figure 3c, ANF transcripts were dramatically upregulated (24-fold), whereas $\alpha \mathrm{MHC}$ was downregulated (12-fold) in hypertrophic transgenic hearts. GAPDH transcripts were measured to correct for differences in RNA amounts between the samples (Figure 3c).

Transthoracic echocardiography in CaMKIV transgenic mice. On the basis of histological sections from CaMKIV transgenic hearts at 2 months of age, we observed an increase in wall thickness without significant increases of the inner ventricular radius, consistent with parallel sarcomere replication in concentric hypertrophy (40). However, at 6 months of age, cardiac wall thickening was frequently accompanied by ventricular dilation, suggesting progression from concentric hypertrophy to a dilated hypertrophic phenotype. To correlate abnormalities further in cardiac structure (as observed in histological section) and function, we measured wall thickness, ventricular diameter, and cardiac function by transthoracic echocardiography in 3-and 6-month-old transgenic mice and wildtype littermates. At 3 months, IVSD, LVEDD, and LVPWD in transgenic mice were increased by $18 \%, 20 \%$, and $29 \%$, respectively. Furthermore, in transgenic mice, LVESD was increased by $27 \%$, and the calculated $\mathrm{LVm}$
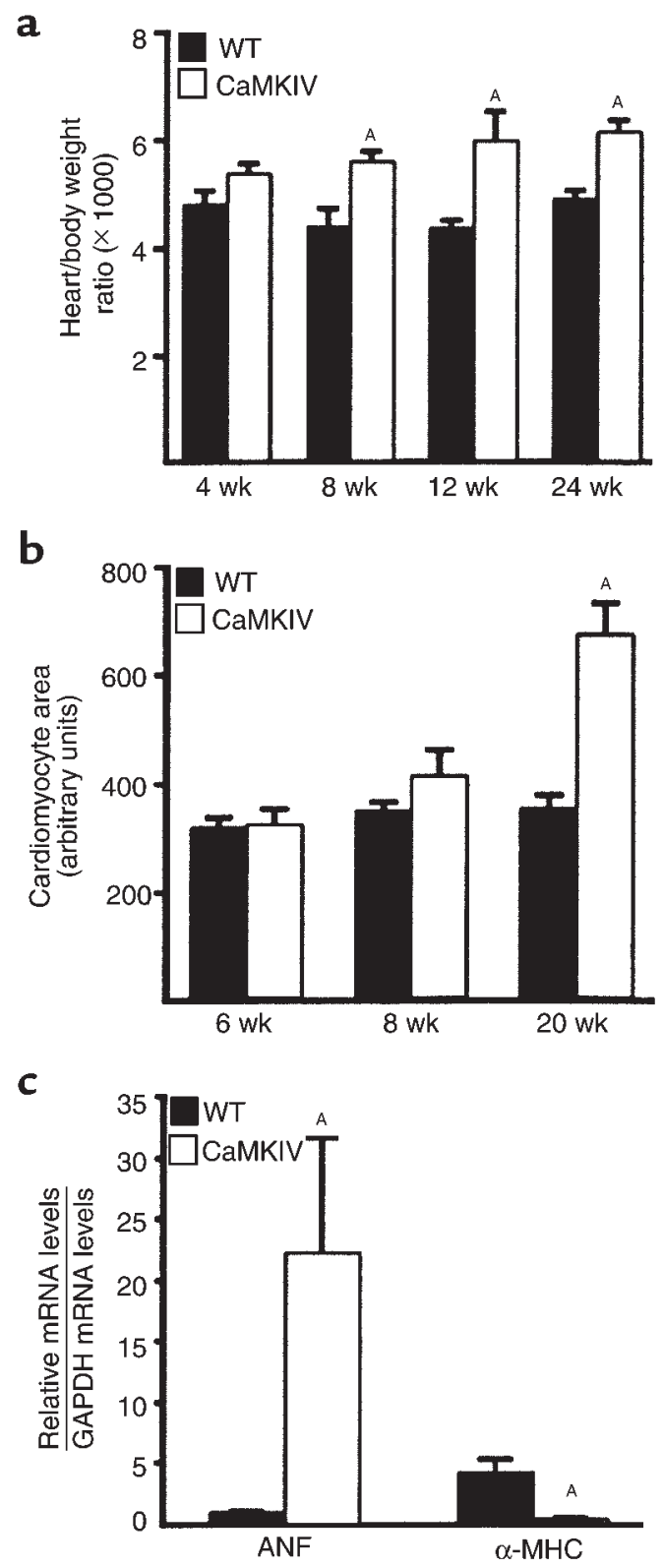

Figure 3

Cardiac hypertrophy in CaMKIV transgenic mice. (a) Heart weight/body weight ratios $(\times 1,000)$ from wild-type $(W T)$ and CaMKIV transgenic mice ( $n=6$ for each group) were measured at 4 , 8,12 , and 24 weeks (wk) of age. (b) Myocyte area per nucleus was measured in WT and CaMKIV transgenic hearts at 6,8 , and 20 weeks ( $n=6$ for each group). (c) Northern hynbridization analysis of ANF and $\alpha$ MHC mRNA levels in WT $(n=5)$ and CaMKIV transgenic mice $(n=6)$ at 3 months of age, divided by GAPDH mRNA levels. Data are presented as mean \pm SEM. ${ }^{A} P<0.05$ versus WT animals. 
was increased by $77 \%$, whereas the heart rate (HR) was decreased by $23 \%$. Although cardiac function, measured by FS, was not significantly different in wild-type and transgenic mice at 3 months of age, a trend toward decreased FS was observed in transgenic mice (Table 1).

At 6 months of age, LVEDD and LVESD in transgenic mice were significantly increased by $21 \%$ and $64 \%$, respectively (Figure 5 and Table 1). Accordingly, FS was decreased by $37 \%$ in transgenic mice. The calculated $\mathrm{LVm}$ was also increased by $43 \%$ in 6 -month old transgenic mice (Table 1). These data demonstrate that early-onset hypertrophy at 3 months of age in CaMKIV transgenic mice, with no significant change in cardiac function, is accompanied by a moderate increase in left ventricular chamber dilation. By 6 months, cardiac dysfunction progresses to dilated cardiomyopathy with pronounced left ventricular chamber dilation, and significantly reduced $\mathrm{FS}$.

Synergy between CaMKIV and calcineurin/NFAT3 pathways in vivo. Previously, we showed that expression of a constitutively active mutant form of NFAT3, called NFAT $\Delta 317$, in the heart resulted in hypertrophy (12). To begin to investigate the potential relationship between the CaMKIV and NFAT signaling pathways, we intercrossed mice expressing the $\alpha M H C-C a M K I V$ and $\alpha \mathrm{MHC}-\mathrm{NFAT} \Delta 317$ transgenes. At 6-8 weeks of age, hypertrophy in each line was relatively modest, whereas in the double transgenics, hypertrophy was greatly enhanced (Figure 6). Several attempts were also made to intercross $\alpha \mathrm{MHC}$-calcineurin and $\alpha \mathrm{MHC}-\mathrm{CaMKIV}$ transgenic mice. We were only able to obtain one double transgenic mouse, which displayed severe dilated cardiomyopathy at 3 weeks of age. None of the CaMKIV or the calcineurin transgenics displayed this cardiac phenotype at 3 weeks of age (data not shown).These results suggest that the CaMKIV and calcineurin/ NFAT3 pathways can synergize to control cardiac growth. Hypertrophy in response to NFAT $\Delta 317$ is less pronounced than for activated calcineurin, which is likely to explain why NFATA317/CaMKIV double transgenics showed greater viability than calcineurin/CaMKIV mice.

CaMK signaling specifically stimulates activity of the MEF2 transcription factor in vivo. MEF2 transcription factors regulate numerous cardiac genes and have been shown to act as end points in $\mathrm{Ca}^{2+}$-dependent signal- ing pathways (reviewed in ref. 29). To determine whether MEF2 might be a downstream target for CaMKIV signaling in the heart, we intercrossed the aMHC-CaMKIV transgenics with MEF2-indicator mice, which harbor a lac $Z$ transgene under transcriptional control of three tandem copies of the MEF2 consensus binding site (34). This MEF2-dependent lac $Z$ reporter gene is expressed throughout the embryonic heart (34), reflecting the important role of MEF2 factors in activation of muscle-specific gene expression during development (41).

Although MEF2 protein is expressed at high levels in the adult heart $(42,43)$, the MEF2-dependent lacZ transgene was not expressed above background levels in the heart after birth (Figure 7a), consistent with the notion that MEF2 factors require specific signaling events or cofactors for activation. Indeed, the MEF2lacZ transgene was upregulated to extremely high levels of expression throughout the heart when it was introduced by breeding into the $\alpha$ MHC-CaMKIV transgenic line (Figure 7a). Quantitative $\beta$-galactosidase assays on cardiac extracts showed a greater than 100 -fold increase in expression of the lac $Z$ transgene in the heart in response to CaMKIV (Figure 7b), demonstrating that CaMK signaling is a potent inducer of MEF2 activity in cardiomyocytes in vivo.

To assess the specificity of the response of the MEF2lacZ reporter to CaMK signaling, we assayed its expression in $\alpha M H C$-calcineurin transgenic mice, which show a much more profound hypertrophic response than the $\alpha M H C-C a M K I V$ transgenics (12). Despite the extreme hypertrophy in $\alpha \mathrm{MHC}$-calcineurin transgenics, the MEF2-lacZ transgene was activated only about eightfold in hearts from these mice, based on quantitative $\beta$-galactosidase assays (Figure $7 \mathrm{~b}$ ). In contrast to $\alpha M H C-C a M K I V$ transgenics, which showed extremely high lacZ staining throughout the heart, staining was observed only sporadically in cardiomyocytes from $\alpha \mathrm{MHC}$-calcineurin transgenics, as seen in histological cross-sections (Figure 7a).

In transgenic mice bearing the hsp-lac $Z$ transgene linked to multimers of a mutant MEF2 site, there was no lacZ expression (data not shown). These results demonstrate the dependence of transgene expression on MEF2 binding in vivo.

Table 1

Echocardiographic parameters for wild-type (WT) and CaMKIV transgenic mice

\begin{tabular}{|c|c|c|c|c|c|}
\hline & $\begin{array}{l}\text { IVSD } \\
(\mathrm{cm})\end{array}$ & $\begin{array}{l}\text { LVEDD } \\
(\mathrm{cm})\end{array}$ & $\begin{array}{l}\text { LVPWD } \\
(\mathrm{cm})\end{array}$ & $\begin{array}{l}\text { IVSS } \\
(\mathrm{cm})\end{array}$ & $\begin{array}{l}\text { LVESD } \\
(\mathrm{cm})\end{array}$ \\
\hline $\begin{array}{l}\text { WT } \\
\text { (3 months) }\end{array}$ & $0.067 \pm 0.002$ & $0.348 \pm 0.018$ & $0.059 \pm 0.006$ & $0.135 \pm 0.004$ & $0.184 \pm 0.010$ \\
\hline $\begin{array}{l}\text { CaMKIV } \\
\text { (3 months) }\end{array}$ & $0.079 \pm 0.003^{\mathrm{A}}$ & $0.419 \pm 0.017^{\mathrm{A}}$ & $0.076 \pm 0.004^{A}$ & $0.141 \pm 0.005$ & $0.251 \pm 0.021^{A}$ \\
\hline $\begin{array}{l}\text { WT } \\
\text { ( } 6 \text { months) }\end{array}$ & $0.072 \pm 0.002$ & $0.388 \pm 0.013$ & $0.068 \pm 0.003$ & $0.136 \pm 0.003$ & $0.207 \pm 0.010$ \\
\hline $\begin{array}{l}\text { CaMKIV } \\
\text { (6 months) }\end{array}$ & $0.075 \pm 0.002$ & $0.468 \pm 0.030^{\mathrm{A}}$ & $0.069 \pm 0.002$ & $0.124 \pm 0.006$ & $0.339 \pm 0.039^{8}$ \\
\hline
\end{tabular}




\section{Figure 4}

Hearts from wild-type and CaMKIV transgenic mice. Whole hearts from wild-type (a) and CaMKIV transgenic (b) mice. Hearts from wild-type (c) and CaMKIV transgenic (d) mice, cut at the midsagittal level and parallel to the base. The same sections of wild-type (e) and CaMKIV transgenic (f) hearts are presented at a higher magnification $(\times 40)$, showing cardiomyocyte enlargement in the transgenic hearts. All hearts were collected from 6-month-old mice. Iv, left ventricle; $r v$, right ventricle.

CaMK signaling does not alter MEF2 DNA binding activity in vivo. We next investigated whether the dramatic increase in MEF2 transcriptional activity in response to CaMK signaling was accompanied by an increase in MEF2 DNA binding activity. Extracts were prepared from wild-type, $\alpha \mathrm{MHC}-\mathrm{CaMKIV}$, and $\alpha \mathrm{MHC}$-calcineurin transgenic mice and tested for MEF2 DNA binding activity by gel mobility shift assays with a ${ }^{32} \mathrm{P}-$ labeled MEF2 binding site as probe. The level of MEF2 DNA binding activity was comparable in cardiac extracts from wild-type, $\alpha \mathrm{MHC}$-CaMKIV, and $\alpha \mathrm{MHC}$ calcineurin (Figure 7c) mice. Thus, despite a greater than 100-fold increase in transcriptional activity of MEF2 in hearts from $\alpha M H C-C a M K I V$ transgenics, there appeared to be no difference in MEF2 DNA binding activity, suggesting that CaMK signaling activates preexisting MEF2 protein.

To confirm that all binding activity observed with this assay was attributable to MEF2, we performed antibody "supershift" assays. In the presence of anti-MEF2A antibody, the entire MEF2-DNA complex was supershifted to a slower-migrating ternary complex, indicating that all of the MEF2 binding activity is composed of either MEF2A homo- or heterodimers (Figure 7c). Previous studies have demonstrated that this antibody is specific for MEF2A and does not recognize other MEF2 isoforms (our unpublished observations). Western blot analysis of cardiac extracts with anti-MEF2A antibody also confirmed that there was no difference in the amount of MEF2 protein in extracts from wild-type and hypertrophic mice (data not shown).
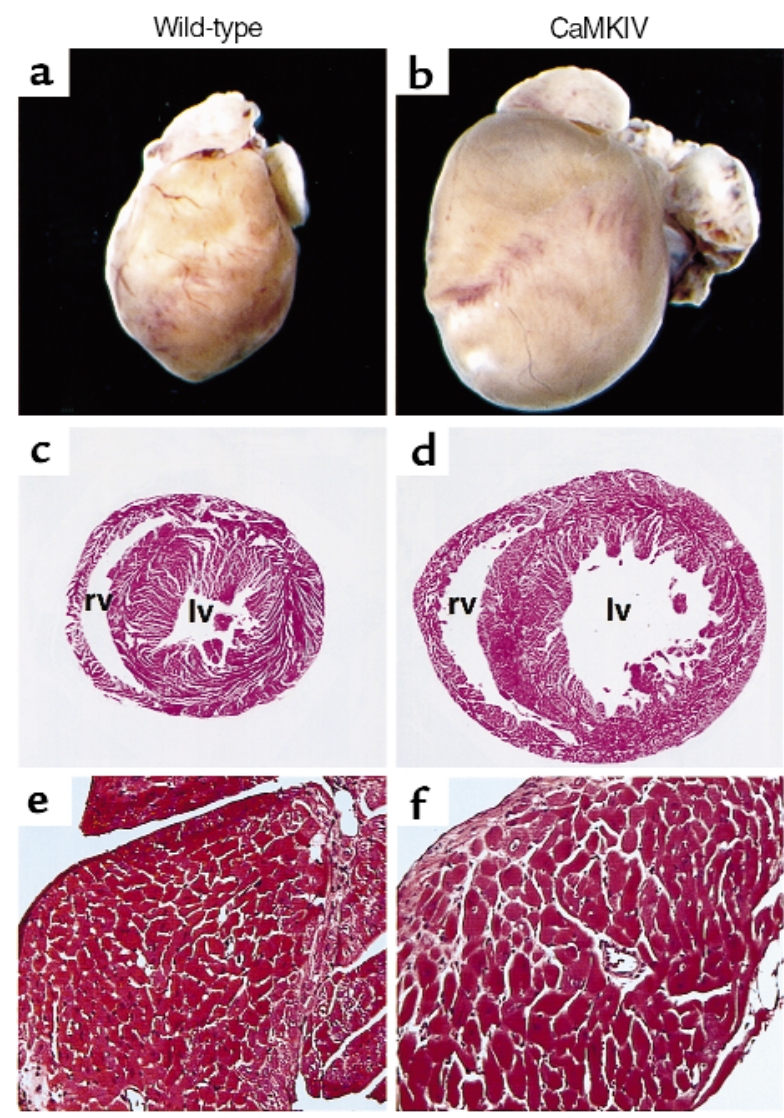

d
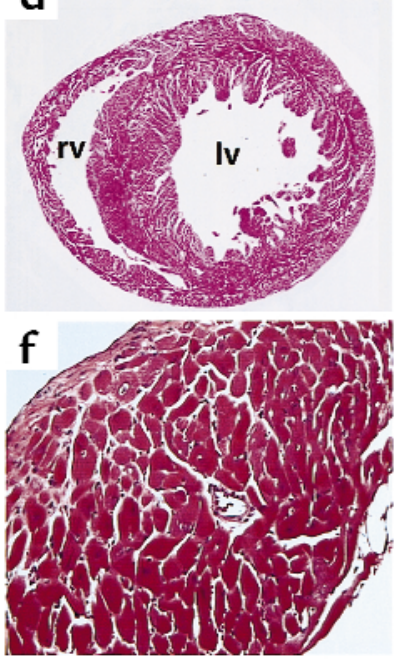

\section{Discussion}

The results of this study show that CaMK signaling induces cardiac hypertrophy through a mechanism leading to posttranslational activation of the MEF2 transcription factor and that the CaMK pathway cooperates with the calcineurin/NFAT3 pathway in the heart in vivo. A model to account for our findings is shown in Figure 8. According to this model, the CaMK and calcineurin signaling pathways act in parallel to preferentially target MEF2 and NFAT, respectively. Because CaMK activation occurs in response to high-amplitude $\mathrm{Ca}^{2+}$ waves, whereas calcineurin is activated by sustained, low-amplitude $\mathrm{Ca}^{2+}$ transients (44), some hypertrophic stimuli could preferentially acti-

Table 1 (Continued)

Echocardiographic parameters for wild-type (WT) and CaMKIV transgenic mice

\begin{tabular}{|c|c|c|c|c|}
\hline & $\begin{array}{l}\text { LVPWS } \\
(\mathrm{cm})\end{array}$ & $\begin{array}{l}\mathrm{LVm} \\
\left(\mathrm{cm}^{3}\right)\end{array}$ & $\begin{array}{l}\text { FS } \\
(\%)\end{array}$ & $\begin{array}{c}\text { HR } \\
(\text { bpm) }\end{array}$ \\
\hline onths) & $0.114 \pm 0.005$ & $0.066 \pm 0.009$ & $47.1 \pm 1.2$ & $427 \pm 27$ \\
\hline $\begin{array}{l}\text { KIV } \\
\text { onths) }\end{array}$ & $0.115 \pm 0.004$ & $0.117 \pm 0.010^{B}$ & $40.9 \pm 2.5$ & $327 \pm 26^{A}$ \\
\hline onths) & $0.118 \pm 0.003$ & $0.089 \pm 0.005$ & $46.8 \pm 3.9$ & $337 \pm 32$ \\
\hline onths) & $0.102 \pm 0.008$ & $0.127 \pm 0.01^{\mathrm{B}}$ & $29.4 \pm 4.0^{C}$ & $292 \pm 8$ \\
\hline
\end{tabular}

Data are presented as mean \pm SEM. For WT, $n=7$ animals; for CaMKIV, $n=9$ animals. ${ }^{A} P<0.05$ versus WT animals. ${ }^{B} P<0.01$ versus WT animals. ${ }^{C} P<0.001$ versus $\mathrm{WT}$ animals. 
Figure 5

Transthoracic echocardiography in wild-type and CaMKIV transgenic mice. Representative M-mode images (bottom) and ECG (top) of wild-type (a) and CaMKIV transgenic (b) mice at 6 months of age. IVS, interventricular septum; LV, left ventricle; PW, posterior wall.

vate one pathway or the other, whereas some stimuli that mobilize different $\mathrm{Ca}^{2+}$ pools could potentially activate both pathways. In the latter case, an especially pronounced hypertrophic response, as seen in CaMKIV/NFAT 317 double transgenics, would be expected. The ability of calmodulin overexpression to induce hypertrophy in vivo (23) or of the calmodulin inhibitor W-7 to prevent induction of hypertrophicresponsive genes by electrical stimulation of contraction of cardiomyocytes in vitro (45) could be explained by one or both of these pathways.

Parallel and cooperative calmodulin-dependent pathways leading to cardiac bypertrophy. Our results support the conclusion that the CaMK and calcineurin pathways for hypertrophic signaling are separate, but there is crosstalk between the pathways as revealed by the partial decrease in CaMK responsiveness in the presence of CsA and by the weak, but measurable, activation of MEF2dependent transcription in vivo by calcineurin. The finding that the CaMK and calcineurin signaling pathways cooperate to induce cardiac hypertrophy in vivo is consistent with the cooperativity between these pathways in other cell types. In T cells, for example, CaMKIV and calcineurin have been shown to act synergistically to activate cytokine genes $(46,47)$, and in skeletal muscle, these pathways synergistically activate slow fiber-
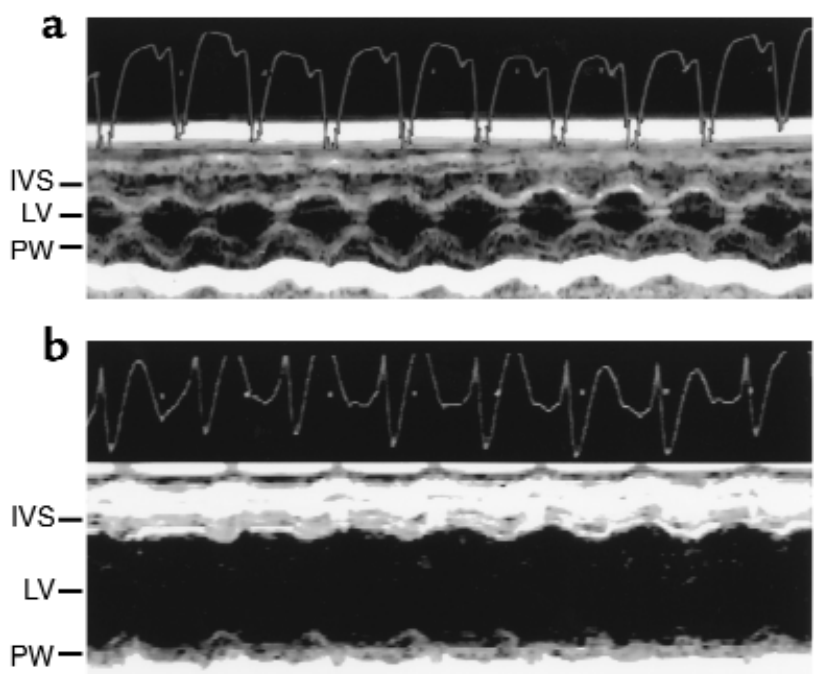

specific genes (48). Activated CaMKIV has also been shown to reconstitute transcriptional activity of the cytosolic component of NFAT in non-T cells and to activate the AP-1 transcription factor, which is an integral component of NFAT transcriptional complexes (46).

The results from this and previous studies (12) demonstrate that MEF2 and NFAT are transcriptional targets for CaMK and calcineurin, respectively, in the heart. Moreover, it appears that NFAT3 activation is sufficient to induce hypertrophy (12). However, whether these transcription factors are essential for the hypertrophic growth in response to these or other signaling pathways remains to be determined. A recent report that cardiac expression of a dominant negative a

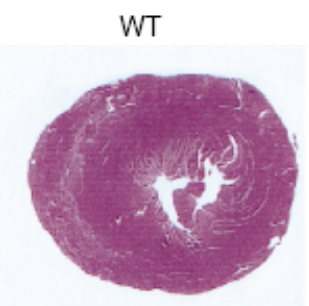

NFAT $\wedge 317$

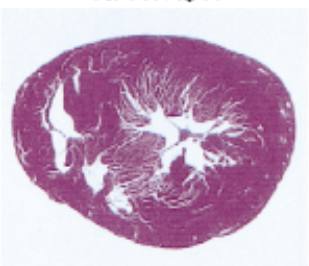

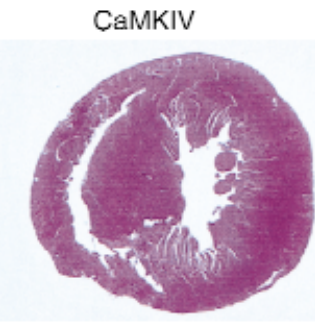

CaMKIV + NFAT $\Delta 317$

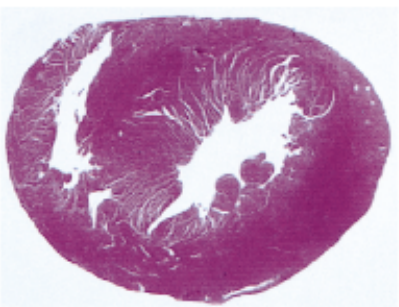

b

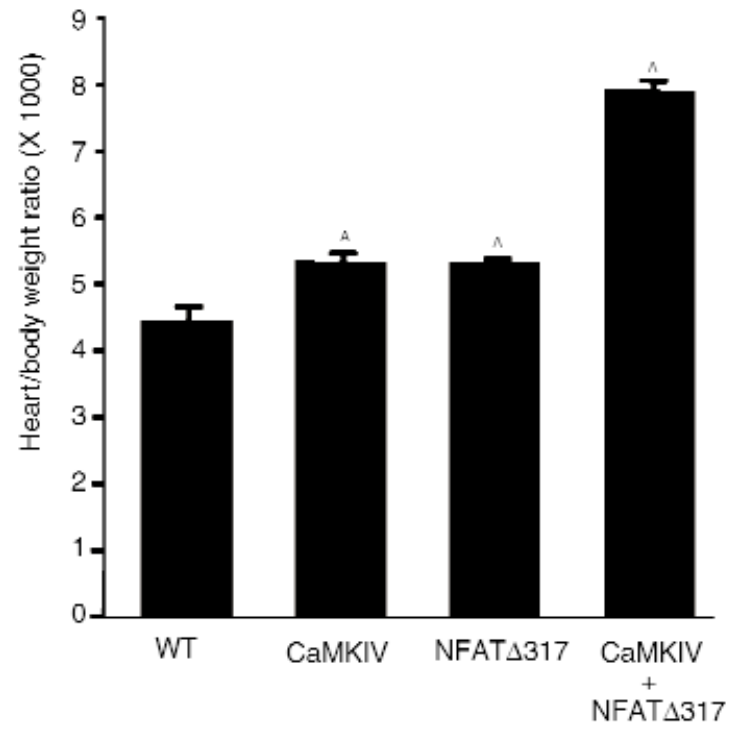

\section{Figure 6}

Intercrosses between the CaMKIV and NFAT 317 transgenic mice. (a) Histological sections of wild-type, CaMKIV, NFAT 317 , and CaMKIV + NFAT $\Delta 317$ transgenic mice at 6 weeks of age. All sections were cut at the midsagittal level and parallel to the base. (b) Heart weight/body weight ratio $(\times 1,000)$ of wild-type $(\mathrm{WT})$, CaMKIV, NFAT $\Delta 317$, and CaMKIV + NFAT $\Delta 317$ at $6-8$ weeks of age $(n=5$ for each group). ${ }^{A} P<0.05$ versus WT animals. 
a

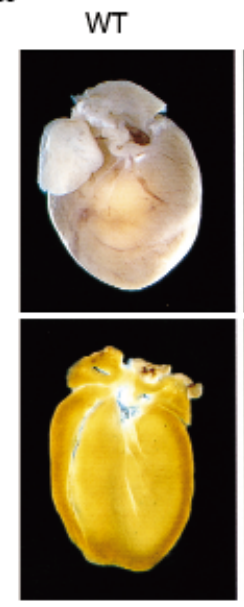

WT b

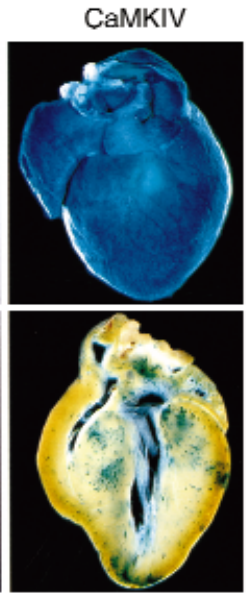

$\mathrm{CN}$
C

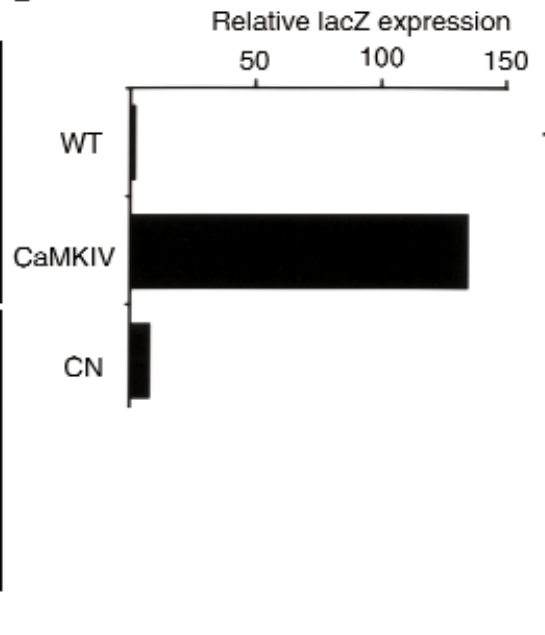

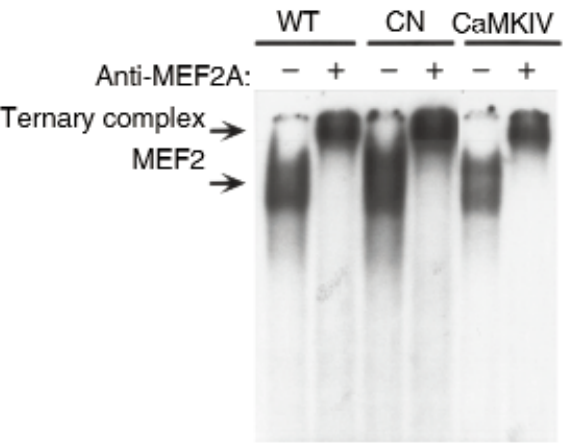

\section{Figure 7}

CaM kinase-dependent activation of MEF2 in vivo. (a) Induction of MEF2 activity by CaMKIV in the intact heart. MEF2 indicator mice were bred with mice harboring an $\alpha \mathrm{MHC}$-CaMKIV or $\alpha \mathrm{MHC}$-calcineurin $(\mathrm{CN})$ transgenes, as described in the text. Littermates positive for the lacZ transgene and lacking (left) or containing the CaMKIV or calcineurin transgene were sacrificed at 8 weeks of age, and hearts were stained for lacZ expression. LacZ expression was not detected above background levels in control hearts, whereas lacZ expression was detected throughout the CaMKIV transgenic heart. In $\alpha \mathrm{MHC}$-calcineurin transgenics, lacZ staining was observed sporadically in subsets of hypertrophic cardiomyocytes. This was revealed more clearly in histological cross section (lower panels). (b) $\beta$-Galactosidase assays were performed on cardiac extracts from wild-type, $\alpha \mathrm{MHC}$-CaMKIV, and $\alpha \mathrm{MHC}$-calcineurin transgenic mice harboring the MEF2-lacZ transgene, as described in Methods. (c) Extracts were prepared from hearts of wild-type, $\alpha \mathrm{MHC}$-CaMKIV, and $\alpha \mathrm{MHC}$-calcineurin transgenic littermates and used for gel mobility shift assays with a ${ }^{32} \mathrm{P}$-labeled MEF2 site as probe. Anti-MEF2A antibody was added to assays as indicated. Comparable amounts of MEF2 DNA binding activity were detected in both extracts, and all activity was supershifted with anti-MEF2A antibody. Nonimmune serum had no effect on the MEF2-DNA protein complex (data not shown). Only the region of the gel containing the shifted probe is shown.

MEF2 mutant prevents postnatal cardiac growth raises the possibility that MEF2 is an essential regulator of cardiac growth (49).

MEF2 and NFAT have been shown to activate some genes cooperatively by binding adjacent sites, raising the possibility that they converge on common downstream target genes in the hypertrophic signaling pathway (50). However, other transcription factors have also been shown to participate in activation of fetal cardiac genes in response to hypertrophy (51-56). Thus, MEF2 and NFAT may activate cascades of subordinate regulators or act as part of a larger transcriptional program for hypertrophy. Indeed, there is evidence to suggest that MEF2 acts through an indirect mechanism to regulate certain genes controlled by serum response factor (57), which is thought to participate in hypertrophy (54).

CaMK signaling in the heart. Numerous studies have suggested a role for CaMKs in hypertrophic signaling. CaMK activity is elevated in failing human hearts (27, 28), consistent with our findings that activated CaMK induces hypertrophy that progresses to failure. CaMKII- $\delta_{\mathrm{B}}$ has been shown to selectively activate the ANF promoter in cultured cardiomyocytes (24). Although the CaMK inhibitor KN-93 blocks the hypertrophic response of primary cardiomyocytes to $\mathrm{PE}$, CaMKII- $\delta_{\mathrm{B}}$ was shown to increase ANF expression without increasing myofibrillar organization in cardiomyocytes (24). These studies suggest other CaMK isoforms are required for the complete hypertrophic response to $\mathrm{PE}$. Induction of cardiac hypertrophy by ET-1 in vitro can be completely blocked by the PKC inhibitor H-7 and KN-62, whereas only partial inhibition is observed with either inhibitor alone (26). These observations further underscore the cooperativity of CaMK signaling with other signaling pathways.

CaMKI and -IV showed equivalent hypertrophic activity when assayed for their ability to stimulate the $A N F$ and $\alpha$-skeletal actin promoters. Both of these kinases are activated by CaM kinase kinase (58). CaMKI is expressed in a wide range of tissues, including the heart, whereas CaMKIV is expressed predominantly in brain, testis, spleen, and thymus (refs. 39 and 59; reviewed in ref. 60). Low levels of CaMKIV expression have also been detected in the heart (39).

Although our results demonstrate that signaling by CaMKIV can evoke a hypertrophic response leading to MEF2 activation, they do not allow us to conclude that CaMKIV is the actual CaMK isoform that might mediate this response in vivo. Indeed, the relatively low level of CaMKIV expression in the heart suggests that other CaMK isoforms may be more likely to participate in this signaling pathway. As pointed out previously (4), it should also be emphasized that results obtained by forced expression of activated signaling molecules in the heart can identify possible pathways influencing cardiac function, but such studies must ultimately be confirmed by other gain- or loss-of-function approaches. Posttranslational activation of MEF2 by CaMK signaling. 


\section{Figure 8}

Calmodulin-dependent transcriptional pathways for cardiac hypertrophy. Activated calcineurin has been shown to act through NFAT3, which associates with GATA4, to induce hypertrophy (12). Activated CaMK stimulates transcriptional activity of MEF2 through a posttranslational mechanism. Calcineurin only weakly activates MEF2 in the heart (indicated by a broken line).

Members of the MEF2 family of transcription factors regulate the expression of numerous muscle-specific and growth factor-inducible genes (reviewed in ref. 29). Although these factors are highly enriched in muscle cells, they are also expressed in other cell types. Our results using MEF2 indicator mice lead to the surprising conclusion that MEF2 protein in the normal adult heart is largely inactive, but can be switched to an active form in response to CaMK signaling. CaMK-dependent activation of MEF2 occurred without a measurable change in MEF2 DNA binding activity. These findings demonstrate that CaMKIV signaling unmasks the transcriptional potential of preexisting MEF2 protein through a posttranslational mechanism in vivo. Although calcineurin has been also shown to stimulate MEF2 activity in transfection assays $(50,61)$, calcineurin was a relatively weak activator of the MEF-lacZ transgene in the hearts of MEF2 indicator mice. Similarly, MAP kinase signaling has been shown to stimulate MEF2 activity in transfection assays (reviewed in ref. 62), but transgenic mice expressing the activated MAP kinase kinase MEK5, which is known to phosphorylate the MEF2 transcription activation domain, in the heart fail to upregulate the MEF2-lacZ reporter (R. Nicol, F. Naya, and E. Olson, unpublished results). These findings demonstrate that MEF2 activation is a specific consequence of CaMK signaling and not a general response to cardiac hypertrophy and provide in vivo evidence for the independence of the CaMK/MEF2 and calcineurin/NFAT pathways.

In addition to their usefulness in discriminating between various hypertrophic signaling pathways in the heart, MEF2 indicator mice should be useful in identifying stimuli in other tissues, such as brain, $\mathrm{T}$ cells, and skeletal muscle, that result in MEF2 activation. This strategy of using reporters dependent specifically on multimerized consensus sites for transcription factors may also allow the in vivo transcriptional targets of other signaling pathways to be identified.

The mechanism whereby CaMK signaling activates MEF2 in vivo remains to be determined, but recent studies have suggested some possibilities. We have discovered that MEF2 factors interact with class II histone deacetylases (HDACs), resulting in repression of MEF2dependent genes, and that CaMK can activate MEF2 by releasing HDACs (63). CaMKIV has also been reported to directly phosphorylate MEF2, but whether this phosphorylation is responsible for transcriptional activation of the protein has not been determined (64).

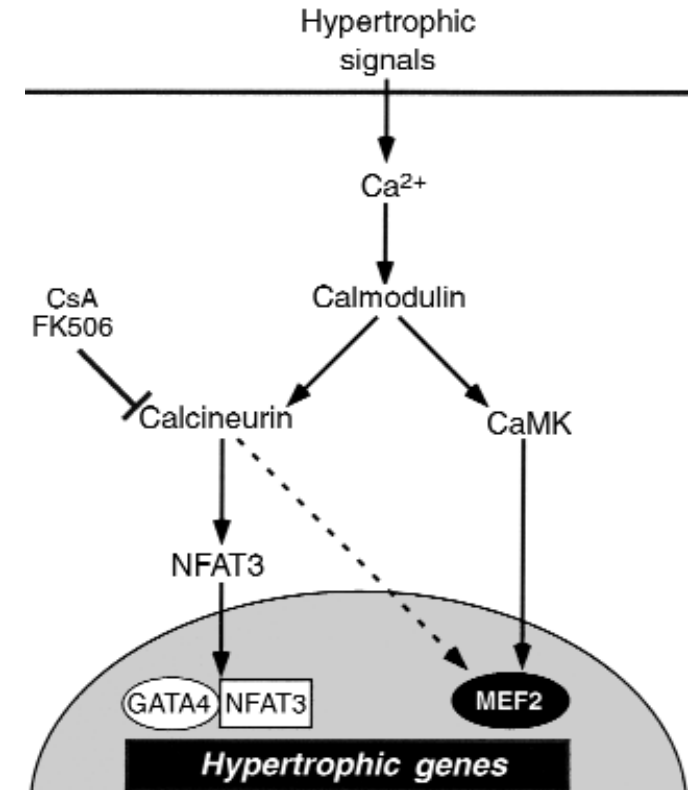

In addition to activating MEF2, CaMKIV has been shown to activate the cAMP-response element-binding protein (CREB) by phosphorylation of serine-133 (65, 66). In this regard, Fentzke et al. have shown that cardiac expression of a dominant negative mutant of CREB, in which serine-133 was replaced with alanine, induces dilated cardiomyopathy without hypertrophy (67). We have examined CREB phosphorylation in hearts of $\alpha M H C-C a M K I V$ transgenic mice at 3 months of age and have found no difference from wild-type (R. Passier and E. Olson, unpublished results). Thus, although CREB phosphorylation may be an acute response to CaMKIV activation, phosphorylated CREB cannot account for the long-term changes in cardiac function in these mice.

Possible nontranscriptional targets for CaMK signaling in the heart. Although we have focused on the possible transcriptional effectors for CaMK signaling in the heart, CaMKs phosphorylate a variety of myocardial proteins involved in $\mathrm{Ca}^{2+}$ handling, such as the ryanodine receptor (68), the sarcoplasmic recticulum $\mathrm{Ca}^{2+}$-ATPase (69), and phospholamban (70), and modulate L-type $\mathrm{Ca}^{2+}$ channels (71), which could influence excitation-contraction coupling in cardiomyocytes. Thus, by altering $\mathrm{Ca}^{2+}$ handling, CaMK activation could evoke a hypertrophic response through an indirect pathway involving altered contractility or function that then results in cardiac hypertrophy. Regardless of whether CaMK signaling leads to hypertrophic growth by acting directly on downstream transcription factors such as MEF2, or by a secondary mechanism, the CaMK signal must ultimately be interpreted in the nucleus to elicit the transcriptional responses associated with hypertrophy. Identification of the transcriptional end points for such pathways represents an important step forward in unraveling the cellular circuitry responsible for normal and abnormal growth of the heart. 


\section{Acknowledgments}

We thank J. Robbins, A. Means, R. Schwartz, T. Chatila, and M. Nemer for reagents; W. Simpson and J. Page for editorial assistance; and A. Tizenor for graphics. This work was supported by grants from the National Institutes of Health (NIH), The Robert A. Welch Foundation, and the Texas Advanced Technology Program to E.N. Olson. R. Passier was supported by The Royal Netherlands Academy of Arts and Sciences; N. Frey was supported by the Deutsche Forschungsgemeinschaft; F.J. Naya and R.L. Nicol were supported by NIH postdoctoral Fellowships. T.A. McKinsey is a Pfizer Fellow of the Life Sciences Research Foundation.

1. McKinsey, T.A., and Olson, E.N. 1999. Cardiac hypertrophy: sorting out the circuitry. Curr. Opin. Genet. Dev. 9:267-274.

2. Sadoshima, J., and Izumo, S. 1997. The cellular and molecular response of cardiac myocytes to mechanical stress. Annu. Rev. Physiol. 59:551-571.

3. Chien, K.R. 1999. Stress pathways and heart failure. Cell. 98:555-558.

4. MacLellan, W.R., and Schneider, M.D. 1998. Success in failure: modeling cardiac decompensation in transgenic mice. Circulation. 97:1433-1435

5. Sei, C.A., et al. 1991 . The $\alpha$-adrenergic stimulation of atrial natriuretic factor expression in cardiac myocytes requires calcium influx, protein kinase C, and calmodulin-regulated pathways. J. Biol. Chem. 266:15910-15916.

6. Sonnenberg, H. 1986. Mechanisms of release and renal tubular action of atrial natriuretic factor. Fed. Proc. 45:2106-2110.

7. LaPointe, M.C., Deschepper, C.F., Wu, J.P., and Gardner, D.G. 1990 Extracellular calcium regulates expression of the gene for atrial natriuretic factor. Hypertension. 15:20-28.

8. Karliner, J.S., Kariya, T., and Simpson, P.C. 1990. Effects of pertussis toxin on $\alpha 1$-agonist-mediated phosphatidylinositide turnover and myocardial cell hypertrophy in neonatal rat myocytes. Experientia. 46:81-84.

9. Leite, M.F., Page, E., and Ambler, S.K. 1994. Regulation of ANP secretion by endothelin-1 in cultured atrial myocytes: desensitization and receptor subtype. Am. J. Physiol. 267:H2193-H2203.

10. Sadoshima, J., Xu, Y., Slayter, H.S., and Izumo, S. 1993. Autocrine release of angiotensin II mediates stretch-induced hypertrophy of cardiac myocytes in vitro. Cell. 75:977-984.

11. Schaub, M.C., Hefti, M.A., Zeullig, R.A., and Morano, I. 1998. Modulation of contractility in human cardiac hypertrophy by essential myosin light chain isoforms. Cardiovasc. Res. 37:381-404.

12. Molkentin, J.D., et al. 1998. A calcineurin-dependent transcriptional pathway for cardiac hypertrophy. Cell. 17:215-228.

13. Sussman, M.A., et al. 1998. Prevention of cardiac hypertrophy in mice by calcineurin inhibition. Science, 281:1690-1693.

14. Mende, U., et al. 1998. Transient cardiac expression of constitutively active $\mathrm{G} \alpha \mathrm{q}$ leads to hypertrophy and dilated cardiomyopathy by calcineurin-dependent and independent pathways. Proc. Natl. Acad. Sci. USA. 95:13893-13898

15. Taigen, T., De Windt, L.J., Lim, H.W., and Molkentin, J.D. 2000. Targeted inhibition of calcineurin prevents agonist-induced cardiomyocyte hypertrophy. Proc. Natl. Acad. Sci. USA. 97:1196-1201.

16. Zhang, W., et al. 1999. Failure of calcineurin inhibitors to prevent pressure-overload left ventricular hypertrophy in rats. Circ. Res. 84:722-728.

17. Ding, B., et al. 1999. Pressure overload induces severe hypertrophy in mice treated with cyclosporin, an inhibitor of calcineurin. Circ. Res. 84:729-734.

18. Meguro, T., et al. 1999. Cyclosporine attenuates pressure-overload hypertrophy in mice while enhancing susceptibility to decompensation and heart failure. Circ. Res. 84:735-740.

19. Luo, Z., Shyu, K.G., Gulaberto, A., and Walsh, K. 1998. Calcineurin inhibitors and cardiac hypertrophy. Nat. Med. 10:1092-1093.

20. Olson, E.N., and Molkentin, J.D. 1999. Prevention of cardiac hypertrophy by calcineurin inhibition: hope or hype? Circ. Res. 84:623-632.

21. Muller, J.G., Nemoto, S., Laser, M., Carabello, B.A., and Menick, D.R. 1998. Calcineurin inhibition and cardiac hypertrophy [letter]. Science 282:1007

22. Shimoyama, M., et al. 1999. Calcineurin plays a critical role in pressure overload-induced cardiac hypertrophy. Circulation. 100:2449-2454.

23. Gruver, C.L., DeMayo, F., Goldstein, M.A., and Means, A.R. 1993. Targeted developmental overexpression of calmodulin induces proliferative and hypertrophic growth of cardiomycytes in transgenic mice. Endocrinology. 133:376-388.
24. Ramirez, M.T., Zhao, X.L., Schulman, H., and Brown, J.H. 1997. The nuclear deltaB isoform of $\mathrm{Ca}^{2+} /$ calmodulin-dependent protein kinase II regulates atrial natriuretic factor gene expression in ventricular myocytes. J. Biol. Chem. 272:31203-31208.

25. McDonough, P.M., Stella, S.L., and Glembotski, C.C. 1994. Involvement of cytoplasmic calcium and protein kinases in the regulation of atrial natriuretic factor secretion by contraction rate and endothelin. J. Biol. Chem. 269:9466-9472.

26. Irons, C.E., Sei, C.A., Hidaka, H., and Glembotski, C.C. 1992. Protein kinase $\mathrm{C}$ and calmodulin kinase are required for endothelin-stimulated trial natriuretic factor secretion from primary atrial myocytes. J. Biol. Chem. 267:5211-5216.

27. Kirchhefer, U., Schmitz, W., Scholz, H., and Neumann, J. 1999. Activity of cAMP-dependent protein kinase and $\mathrm{Ca}^{2+} /$ calmodulin-dependent protein kinase in failing and nonfailing human hearts. Cardiovasc. Res. 42:254-261.

28. Hoch, B., Meyer, R., Hetzer, R., Krause, E.-G., and Karczewski, P. 1999. Identification and expression of $\mathrm{d}$-isoforms of the multifunctional $\mathrm{Ca}^{2+} /$ calmodulin-dependent protein kinase in failing and nonfailing human myocardium. Circ. Res. 84:713-721.

29. Black, B., and Olson, E.N. 1998. Transcriptional control of muscle development by myocyte enhancer factor-2 (MEF2) proteins. Annu. Rev. Cell Dev. Biol. 14:167-196.

30. McBride, K., Robitaille, L., Tremblay, S., Argentin, S., and Nemer, M. 1993. Fos/jun repression of cardiac-specific transcription in quiescent and growth-stimulated myocytes is targeted at a tissue-specific cis element. Mol. Cell. Biol. 13:600-612.

31. MacLellan, W.R., Lee, T., Schwartz, R.J., and Schneider, M.D. 1994. Transforming growth factor-response elements of the skeletal $\alpha$-actin gene. J. Biol. Chem. 269:16754-16760.

32. Gulick, J., Subramaniam, A., Neumann, J., and Robbins, J. 1991. Isolation and characterization of the mouse cardiac myosin heavy chain genes. J. Biol. Chem. 266:9180-9185.

33. Chatila, T., Anderson, K.A., Ho, N., and Means, A.R. 1996. A unique phosphorylation-dependent mechanism for the activation of $\mathrm{Ca}^{2+} /$ calmodulin-dependent protein kinase type IV/GR. J. Biol. Chem. 271:21542-21548.

34. Naya, F.J., Wu, C., Richardson, J.A., Overbeek, P., and Olson, E.N. 1999. Transcriptional activity of MEF2 during mouse embryogenesis monitored with a MEF2-dependent transgene. Development. 126:2045-2052.

35. Miller, J.M. 1972. Assays for $\beta$-galactosidase. In Molecular genetics. J.M. Miller, editor. Cold Spring Harbor Laboratory Press. Cold Spring Harbor, New York, USA. 352-355.

36. Hogan, B., Constanini, F., and Lacy, E. 1986. Manipulating the mouse embryo: a laboratory manual. Cold Spring Harbor Laboratory Press. Cold Spring Harbor, New York, USA. 497pp.

37. Gardin, J.M., et al. 1995. Echocardiographic assessment of left ventricular mass and systolic function in mice. Circ. Res. 76:907-914.

38. Gossett, L.A., Kelvin, D.J., Sternberg, E.A., and Olson, E.N. 1989. A new myocyte-specific enhancer-binding factor that recognizes a conserved element associated with multiple muscle-specific genes. Mol. Cell. Biol. 9:5022-5033.

39. Miyano, O., Kameshita, I., and Fujisawa, H. 1992. Purification and characterization of a brain-specific multifunctional calmodulin-dependent protein kinase from rat cerebellum. J. Biol. Chem. 267:1198-1203.

40. Devereux, R.B., and Roman, M.J. 1999. Left ventricular hypertrophy in hypertension: stimuli, patterns, and consequences. Hypertens. Res. 22:1-9.

41. Lin, Q., Schwarz, J., Buchana, C., and Olson, E.N. 1997. Control of cardiac morphogenesis and myogenesis by the myogenic transcription factor MEF2C. Science. 276:1404-1407.

42. Yu, Y.T., et al. 1992. Human myocyte-specific enhancer factor 2 comprises a group of tissue-restricted MADS box transcription factors. Genes Dev. 6:1783-1798.

43. Breitbart, R.E., et al. 1993. A fourth human MEF2 transcription factor, hMEF2D, is an early marker of the myogenic lineage. Development. 118:1095-1106.

44. Dolmetsch, R.E., Lewis, R.S., Goodnow, C.C., and Healy, J.I. 1997. Differential activation of transcription factors induced by $\mathrm{Ca}^{2+}$ response amplitude and duration. Nature. 386:855-858.

45. McDonough, P.M., and Glembotski, C.C. 1992. Induction of atrial natriuretic factor and myosin light chain-2 gene expression in cultured ventricular myocytes by electrical stimulation of contraction. J. Biol. Chem. 267:11665-11668

46. Ho, N., Gullberg, M., and Chatila, T. 1996. Activation protein 1dependent transcriptional activation of interleukin 2 gene by $\mathrm{Ca}^{2+} /$ calmodulin kinase type IV. J. Exp. Med. 184:101-112.

47. Lobo, F.M., Zanjani, R., Ho, N., Chatila, T.A., and Fuleihan, R.L. 1999. Calcium-dependent activation of TNF family gene expression by $\mathrm{Ca}^{2+} /$ calmodulin kinase type IV/Gr and calcineurin. J. Immunol. 162:2057-2063

48. Wu, H., et al. 2000. MEF2 responds to multiple calcium-regulated sig- 
nals in the control of skeletal muscle fiber type. $E M B O J$. In press.

49. Kolodziejczyk, S.M., et al. 1999. MEF2 is upregulated during cardiac hypertrophy and is required for normal post-natal growth of the myocardium. Curr. Biol. 9:1203-1206.

50. Chin, E.R., et al. 1998. A calcineurin-dependent transcriptional pathway controls skeletal muscle fiber type. Genes Dev. 15:2499-2509.

51. Sadoshima, J., and Izumo, S. 1993. Signal-transduction pathways of angiotensin II-induced c-fos gene expression in cardiac myocytes in vitro. Circ. Res. 73:424-438.

52. Karns, L.R., Kariya, K., and Simpson, P.C. 1995. M-CAT, CArG, and Sp1 elements are required for $\alpha 1$-adrenergic induction of the skeletal $\alpha$-actin promoter during cardiac myocyte hypertrophy. J. Biol. Chem. 270:410-417.

53. Kovacic-Milivojevic, B., Wong, V.S.H., and Gardner, D.G. 1996. Selective regulation of the atrial natriuretic peptide gene by individual components of the activator protein-1 complex. Endocrinology. 137:1108-1117.

54. Paradis, P., MacLellan, W.R., Belaguli, N.S., Schwartz, R.J., and Schneider, M.D. 1996. Serum response factor mediates AP-1-dependent induction of the skeletal $\alpha$-actin promoter in ventricular myocytes. J. Biol. Chem. 271:10827-10833.

55. Herzig, T.C., et al. 1997. Angiotensin II type 1a receptor gene expression in the heart: AP-1 and GATA-4 mediate the response to pressure overload. Proc. Natl. Acad. Sci. USA. 94:7543-7548.

56. Hasegawam, K., Lee, S.J., Jobe, S.M., Markham, B.E., and Kitsis, R.N 1997. Cis-acting sequences that mediate induction of the $\alpha$-myosin heavy chain gene expression during left ventricular hypertrophy due to aortic constriction. Circulation. 96:3943-3953.

57. Lin, Q., et al. 1998. Requirement of the MADS-box transcription factor MEF2C for vascular development. Development. 125:4565-4574.

58. Anderson, K.A., et al. 1998. Components of a calmodulin-dependent protein kinase cascade. Molecular cloning, functional characterization and cellular localization of $\mathrm{Ca}^{2+} /$ calmodulin-dependent protein kinase kinase beta. J. Biol. Chem. 273:31880-31889.

59. Gruzalegui, F.H., and Means, A.R. 1993. Biochemical characterization of the multifunctional $\mathrm{Ca}^{2+} /$ calmodulin-dependent protein kinase IV expressed in insect cells. J. Biol. Chem. 268:26171-26178.

60. Braun, A.P., and Schulman, H. 1995. The multifunctional calcium/calmodulin-dependent protein kinase: from form to function. Annu. Rev. Physiol. 57:417-445.
61. Mao, Z., and Weidmann, M. 1999. Calcineurin enhances MEF2 DNA binding activity in calcium-dependent survival of cerebellar granule neurons. J. Biol. Chem. 274:31102-31107.

62. Naya, J.F., and Olson, E.N. 1999. MEF2: a transcriptional target for signaling pathways controlling skeletal muscle growth and differentiation. Curr. Opin. Cell Biol. 11:683-688.

63. Lu, J., McKinsey, T.A., Nicol, R.L., and Olson, E.N. 2000. Signal-dependent activation of the MEF2 transcription factor by dissociation from histone deacetylases. Proc. Natl. Acad. Sci. USA. 97:4070-4075.

64. Blaeser, F., Ho, N., Prywes, R., and Chatila, T.A. 2000. Ca2+-dependent gene expression mediated by MEF2 transcription factors. J. Biol. Chem. 275:197-209.

65. Sun, P., Enslen, H., Myung, P.S., and Maurer, R.A. 1994. Differential activation of CREB by $\mathrm{Ca}^{2+} /$ calmodulin-dependent protein kinase type II and type IV involves phosphorylation of a site that negatively regulates activity. Genes Dev. 8:2527-2539.

66. Matthews,R.P., et al. 1994. Calcium/calmodulin-dependent protein kinase types II and IV differentially regulate CREB-dependent gene expression. Mol. Cell. Biol. 14:6107-6116.

67. Fentzke, R.C., Korcarz, C.E., Lang, R.M., Lin, H., and Leiden, J.M. 1998. Dilated cardiomyopathy in transgenic mice expressing a dominant-negative CREB transcription factor in the heart. J. Clin. Invest. 101:2415-2426

68. Witcher, D.R., Kovacs, R.J., Schulman, H., Cefali, D.C., and Jones, L.R. 1991. Unique phosphorylation site on the cardiac ryanodine receptor regulates calcium channel activity. J. Biol. Chem. 266:11144-11152.

69. Xu, A., Hawkins, C., and Narayanan, N. 1993. Phosphorylation and activation of the $\mathrm{Ca}^{2+}$-pumping ATPase of cardiac sarcoplasmic reticulum by $\mathrm{Ca}^{2+} /$ calmodulin-dependent protein kinase. J. Biol. Chem. 264:8394-8397.

70. Simmerman, H.K., Collins, J.H., Theibert, L.J., Wegener, A.D., and Jones, L.R. 1986. Sequence analysis of phospholamban. Identification of phosphorylation sites and two major structural domains. J. Biol. Chem. 261:13333-13341.

71. Basavappa, S., Mangel, A.W., Scott, L., and Liddle, R.A. 1998. Activation of calcium channels by cAMP in STC-1 cells is dependent upon $\mathrm{Ca}^{2+} /$ calmodulin-dependent protein kinase II. Biochem. Biophys. Res. Commun. 254:699-702. 